\title{
Desenvolvimento Profissional de Docentes Iniciantes na Educação Especial
}

\author{
Silmara de Oliveira Gomes Papi' \\ 'Universidade Estadual de Ponta Grossa (UEPG), Ponta Grossa/PR - Brasil
}

\begin{abstract}
RESUMO - Desenvolvimento Profissional de Docentes Iniciantes na Educação Especial. O desenvolvimento profissional de docentes iniciantes na profissão e na educação especial é pouco compreendido, mesmo sendo ele relevante para a prática docente e sua melhoria. Neste estudo analisam-se os desafios vivenciados por esses professores, tendo em vista compreender seu desenvolvimento profissional. Participaram da pesquisa professores de Salas de Recursos Multifuncionais (SRM) de escolas estaduais. A pesquisa tem abordagem crítico-dialética e enfoque qualitativo. Os resultados indicam fragilidades no desenvolvimento profissional dos iniciantes, que sentem dificuldades relacionadas à prática pedagógica e à burocracia, mesmo tendo formação específica na área. Sentem-se também estranhos à escola e buscam alternativas para suprir as lacunas existentes em relação à prática profissional. Palavras-chave: Desenvolvimento Profissional. Professores Iniciantes. Educação Especial. Sala de Recursos Multifuncionais.
\end{abstract}

ABSTRACT - Professional Development of Novice Special Education Teachers. The professional development of novice teachers in the profession and in special education is poorly understood, despite its relevance to the improvement of teaching. This study analyzes the challenges faced by such teachers with a view to understanding their professional development. The participants in the research were teachers of classrooms equipped with multifunctional resources (SRM) in state schools. The research follows a critical-dialectic approach and a qualitative focus. The results indicate deficiencies in the professional development of novices, who experience difficulties related to teaching and bureaucracy, despite having specific training in the area. They also feel alienated in the schools and seek alternatives to fill existing gaps related to their professional practice.

Keywords: Professional Development. Novice Teachers. Special Education. Classroom with Multifunctional Resources.

Educação \& Realidade, Porto Alegre, v. 43, n. 2, p. 747-770, abr./jun. 2018. 747 http://dx.doi.org/10.1590/2175-623669053 


\section{Introdução}

O desenvolvimento profissional docente corresponde a um processo dinâmico de avanço do professor na condução das atividades pedagógicas, relacionando-se também ao processo de melhoramento da escola e da aprendizagem dos alunos. Nesse sentido, pensar no desenvolvimento profissional docente significa reconhecer a importância da aprendizagem contínua do professor para atender às demandas do exercício profissional tendo em vista o alcance de avanços na educação escolar.

Estudos sobre o desenvolvimento profissional docente têm destacado a importância dos primeiros cinco anos do exercício da profissão (Imbernón, 1998) quando os professores estão no início da carreira. Conforme indica a literatura, nesses primeiros anos estabelecem-se os pilares sobre os quais irá se constituir a ação docente futura. Daí a relevância do acompanhamento e formação diferenciados voltados a esses professores (Imbernón, 1998; Marcelo, 1999).

No Brasil, pesquisas têm demonstrado que as iniciativas formativas voltadas aos professores iniciantes tiveram avanços. Entretanto, como são ainda situações pontuais, concluiu-se que se fazem necessárias políticas efetivas, que propiciem o atendimento das especificidades desses professores tendo em vista sua aprendizagem e desenvolvimento profissional (André, 2012).

Entre os estudos brasileiros, Roveda et al. (2014) destacaram as dificuldades de professores iniciantes no ensino superior tanto em relação à dimensão humana de sua atuação quanto em relação à dimensão estrutural à qual estavam vinculados. André et al. (2014), por sua vez, apontaram desafios para a constituição da profissionalidade docente e alertaram para a necessidade de apoio pedagógico, afetivo e cognitivo aos professores em início de carreira.

A importância dos primeiros anos do exercício profissional requer que se considere, então, que há uma lacuna em relação a estudos voltados ao desenvolvimento profissional de professores iniciantes na educação especial brasileira, importantes para o avanço das políticas da área.

Tendo em vista que o Brasil definiu como política a educação inclusiva, sobretudo no que diz respeito à inclusão escolar de alunos da educação especial ${ }^{1}$ (Brasil, 2008) que passaram a frequentar com os demais alunos as escolas regulares de educação básica, o conhecimento de aspectos do desenvolvimento profissional do docente iniciante no Atendimento Educacional Especializado (AEE) nessas escolas se faz necessário.

Há que se considerar que existe uma realidade complexa e de múltiplas exigências que se apresenta ao professor do AEE, cujo trabalho passa a ser de apoio à inclusão escolar. Entretanto, segundo Castro e Vaz (2015), nem sempre condições objetivas são viabilizadas para que esse processo se efetive.

748 Educação \& Realidade, Porto Alegre, v. 43, n. 2, p. 747-770, abr./jun. 2018. 
Além disso, conforme dados do Resumo Técnico do Censo Escolar de 2013 do Instituto Nacional de Estudos e Pesquisas Educacionais Anísio Teixeira (Inep), de 2007 a 2013 houve um aumento de 285.923 para 609.839 nas matrículas de alunos da educação especial incluídos em classes comuns da rede pública de ensino brasileira (Instituto..., 2014). Esses números reforçam a demanda de trabalho dos professores de educação especial para atuar com uma parcela desses alunos no AEE e remetem também à importância do desenvolvimento profissional desses professores, sobretudo dos iniciantes.

Sendo escassas as publicações brasileiras que discutem sobre o professor iniciante nessa modalidade de educação, verificou-se que um estudo que se aproxima da temática foi realizado por Marquezine, Leonessa e Busto (2013). As autoras buscaram dados para subsidiar a reformulação de um curso de especialização ofertado por uma instituição de ensino superior pública. O estudo enfocou as principais dificuldades na atuação com alunos com deficiência, segundo professores egressos do curso.

Os participantes da pesquisa, considerados iniciantes, deveriam estar atuando com esses alunos em "[...] escolas especiais, regulares e outros serviços”, sem diferenciação (Marquezine; Leonessa; Busto, 2013, p. 703). Resultados gerais foram obtidos pelas pesquisadoras a partir dos diferentes espaços de atuação dos participantes, mas não se explicitou, entretanto, a indicação do critério utilizado para definir a condição de iniciantes atribuída aos professores para além de serem egressos do curso. As dificuldades indicadas por mais da metade deles foram o desconhecimento sobre a deficiência e como trabalhar com os comportamentos inadequados do aluno, apontadas por $80 \%$ e $54 \%$ dos professores, sucessivamente.

Basurto López (2012), em investigação sobre professores iniciantes na educação especial mexicana, demonstrou que esses professores atuavam em uma realidade que não foi a mesma vivida por eles durante a formação inicial naquele país.

A autora concluiu que a socialização dos iniciantes aconteceu cotidianamente, mas também como uma estratégia associada à comunicação visando à sua colocação junto aos professores do ensino regular uma vez que lhes cabe intervir no processo de aprendizagem "dos alunos com necessidades especiais de educação” (Basurto López, 2012, p. 4). Concluiu ainda que eles sentem certa rejeição por parte dos demais professores. Para Basurto López (2012, p. 3) “[...] é o caso dos especialistas novos que ao chegarem à escola regular encontram formas de vida $\mathrm{e}$ costumes já estabelecidas, que as herdam e que somam a essas as próprias".

Esse processo foi descrito pela autora como "[...] a luta por espaço [...]” (Basurto López, 2012, p. 4), pois concluiu que a entrada do professor da educação especial para colaborar com o ensino regular é percebida como invasiva pelos demais professores.

Educação \& Realidade, Porto Alegre, v. 43, n. 2, p. 747-770, abr./jun. 2018. 
Diante dessas reflexões, o presente artigo se propõe a explicitar os desafios vivenciados por professores iniciantes na profissão e no AEE tendo em vista compreender aspectos de seu desenvolvimento profissional. Os professores iniciantes atuam em Salas de Recursos Multifuncionais $(\mathrm{SRM})^{2}$ de escolas públicas estaduais que ofertam a segunda etapa do ensino fundamental. Para o que se propõe o artigo, apresentam-se considerações teóricas sobre o desenvolvimento profissional docente e o professor iniciante, passando-se à análise e discussão dos dados empíricos. Algumas considerações são tecidas ao final, a partir do estudo realizado.

\section{Desenvolvimento Profissional Docente e Professores Iniciantes}

Estudos clássicos de Jordell (1987) acerca das influências que sofrem os professores iniciantes apontaram a importância dos fatores pessoais e estruturais na prática desses professores. O autor discute sobre como as teorias das práticas e as práticas dos iniciantes são influenciadas principalmente no contexto escolar, incidindo sobre sua aprendizagem e desenvolvimento profissional.

Ao estudar tais influências e tendo como norteadoras as pesquisas de Lundgren (1977 apud Jordell, 1987) e Clark e Peterson (1986 apud Jordell, 1987), Jordell (1987) concluiu que as influências estruturais sobre o professor, que envolvem seu contexto de trabalho e correspondem ao nível da sala de aula, da escola e social, são de relevância mais significativa do que o nível de influência pessoal.

Em relação às influências pessoais, Jordell (1987) verificou que as que envolvem as pessoas com quem os iniciantes interagem, especialmente colegas, alunos, funcionários e pais, são mais importantes para sua prática e socialização do que as que são externas à escola.

Quanto aos influxos estruturais, o autor constatou que:

Como resultado de seu trabalho, professores desenvolverão teorias/crenças e certo comportamento de sala de aula. Isto é em parte devido à influência dos alunos. Mas as molduras estruturais dentro das quais o ensino acontece - tempo, recursos, currículo, livro-texto, número de alunos, aí por diante - são influências mais importantes (Jordell, 1987, p. 175, tradução nossa).

Segundo Jordell (1987) os aspectos estruturais tais como número de alunos, tempo, recursos, geram dificuldades aos iniciantes. Esses aspectos se articulam à estrutura social e institucional e se relacionam a fatores como regras e objetivos existentes na escola, por isso dão um contorno à prática docente.

$\mathrm{O}$ autor ainda concluiu que, com base no que vivenciam, os iniciantes desenvolvem estratégias de sobrevivência e de cópia que compõem suas teorias e crenças. Essas estratégias se manifestam na prática pedagógica na sala de aula, no planejamento e nas decisões tomadas 
(Jordell, 1987). O desenvolvimento profissional, portanto, é um processo complexo que, na perspectiva da melhoria da atuação profissional, articula-se a questões ao mesmo tempo individuais, coletivas e contextuais, vinculando-se a um projeto amplo de educação e escola.

Para que se efetive o desenvolvimento profissional do professor iniciante é indispensável o apoio diferenciado por parte das instâncias superiores de gestão da educação e também da escola, bem como um olhar atento do próprio professor sobre suas necessidades, a fim de buscar superá-las.

O período de iniciação, conforme Marcelo (1999), mesmo se iniciando após a formação inicial, destaca-se substancialmente da formação continuada. Vaillant e Marcelo (2012, p. 125) consideram-no “[...] uma etapa na qual as dúvidas, as inseguranças, a ansiedade por ingressar na prática acumulam-se e convivem sem boa vizinhança”. Por predominarem esses aspectos, segundo os autores, o apoio e os programas específicos não devem ser limitados a “[...] atividades pontuais e espontâneas” (Vaillant; Marcelo 2012, p. 126).

Sendo assim, considerando-se que a aprendizagem da docência é um processo contínuo, o período de iniciação é crucial para que esse processo se fortaleça (Marcelo, 1999). As dúvidas do professor iniciante surgem com a prática da docência, pois nela vivenciam o inusitado. É no período de iniciação, nesses primeiros anos, que pela primeira vez cabe ao professor pensar e conduzir mais autonomamente o processo ensino-aprendizagem, ainda que isso se dê em uma realidade com características sócio-históricas que influenciam sua ação.

É preciso destacar, entretanto, que valorizar esse período não significa menosprezar a necessidade de uma sólida formação inicial para o professor ou, ainda, minimizar a importância da formação continuada ao longo do exercício profissional. Significa, sim, compreender sua relevância nesse contexto, o que demanda investimentos e estrutura favorável para o atendimento de necessidades específicas.

Quando se discute sobre o período de iniciação dos professores da modalidade educação especial há que se considerar que a formação desses professores é controversa. Para Michels (2011), muitas vezes ela tem se caracterizado pelo modelo médico-psicológico, que tem suas bases na biologia e centra-se na aprendizagem de recursos e técnicas específicos relacionados às deficiências, sem a devida observância dos aspectos pedagógicos da escolarização dos alunos, o que pode ser indicativo, segundo a autora, de que a inclusão não esteja pressupondo "[...] a apropriação do conhecimento escolar por parte dos alunos com deficiência” (Michels, 2011, p. 11).

Garcia (2013), em análise documental sobre a formação docente no âmbito das políticas de educação especial no período de 2001 a 2010, também concluiu que há falta de debate pedagógico e de reflexões sobre o trabalho do professor dessa modalidade, destacando, como Michels (2011), que os professores que nela atuam têm "[...] uma formação esvaziada de base teórica e de conteúdo pedagógico [...]”, o que a compro-

Educação \& Realidade, Porto Alegre, v. 43, n. 2, p. 747-770, abr./jun. 2018. 751 
Desenvolvimento Profissional de Docentes Iniciantes na Educação Especial

mete (Garcia, 2013, p. 116). E, estando comprometida a formação docente, compromete-se seu desenvolvimento profissional.

\section{Metodologia da Pesquisa}

Este estudo, de abordagem crítico-dialética (Castoriadis, 1985; Thompson, 1981), tem como eixo epistemológico a teoria como expressão da prática (Martins, 2004). Entende-se que os sujeitos empreendem ações em meio às contradições existentes, resultando em formas de pensar, teorias e conteúdos. A teoria, então, não resulta da realidade enquanto não praticada e o conhecimento produzido se dá mediante relações sociais e instituições.

A pesquisa, que foi aprovada pela Comissão de Ética em Pesquisa envolvendo seres humanos ${ }^{3}$, tem enfoque qualitativo (Triviños, 1987) e envolveu professores atuantes em Salas de Recursos Multifuncionais de escolas públicas que ofertam a segunda etapa do ensino fundamental e pertencem a um Núcleo Regional de Educação (NRE) paranaense.

Na primeira etapa da pesquisa, entendida como uma etapa exploratória, estabeleceu-se contato com o setor específico do NRE para a identificação dos professores atuantes nas SRM. Os dados levantados permitiram concluir que o NRE abrangia onze municípios, os quais contavam no segundo semestre de 2012 com 86 SRM distribuídas em 57 escolas estaduais. O total de professores atuantes nessas salas era de 78 . Esse levantamento se deu de junho a agosto de 2012.

A partir desses dados, de posse da relação de nomes dos 78 professores e das 57 escolas, foi necessário estabelecer outras ações, tendo em vista que o NRE não dispunha de informações sobre o tempo de atuação dos professores na profissão e na educação especial, aspecto necessário para a identificação dos iniciantes.

Por esse motivo, realizou-se contato telefônico com os 78 professores em suas escolas para alguns esclarecimentos sobre a pesquisa (já autorizada pelo NRE) e sobre a necessidade de identificação do tempo de exercício profissional de todos os professores das SRM. Nesse momento eles foram informados de que, caso concordassem, seria encaminhado via e-mail um questionário por meio do qual tal aspecto seria verificado. Os 78 professores se dispuseram a participar dessa etapa. Essa verificação foi morosa por diferentes motivos: dificuldade para encontrar os professores nas escolas, dificuldade quanto à disponibilidade de horário dos professores para que pudessem atender ao telefonema e dificuldade em relação à demora para o retorno dos questionários de identificação para a pesquisadora. Esse levantamento foi realizado de agosto a novembro de 2012 .

A segunda fase, fase mais efetiva da pesquisa, iniciou-se a partir da sistematização dos 78 questionários, quando se verificou que seis professores (7,7\% do total de professores) eram iniciantes na profissão e na educação especial, sendo elegíveis para o estudo proposto.

Os seis professores foram novamente contatados em suas escolas por telefone para o agendamento de uma data viável para a apresenta- 
ção formal do estudo, tendo em vista a necessidade de se realizar uma entrevista semiestruturada para a apreensão de aspectos do desenvolvimento profissional desses professores. Dos seis professores, cinco aceitaram participar da pesquisa $(83,3 \%$ dos iniciantes) e assinaram quando do encontro com a pesquisadora o Termo de Consentimento Livre e Esclarecido. Esses professores pertenciam a três municípios vinculados ao NRE.

Dentre os participantes, quatro tinham idade entre 26 e 40 anos e um tinha idade acima de 40 anos. Quanto ao tempo de exercício profissional, os cinco professores tinham menos de um ano de experiência na SRM. Em relação à atuação no ensino regular, dois professores atuavam há dois anos, dois há três anos e um professor há cinco anos. Todos tinham formação em cursos de licenciatura (educação física, pedagogia e letras português/espanhol) e especialização em educação especial.

Os dados da pesquisa foram coletados em dezembro de 2012 e analisados a partir de análise de conteúdo (Bardin, 2004). Os professores, quatro do sexo feminino e um do sexo masculino, estão identificados aleatoriamente no texto como I1, I2, I3, I4 e I5 (iniciantes 1 a 5).

\section{Análise e Discussão dos Dados}

A análise dos dados empíricos permitiu a percepção de quatro eixos. Esses eixos de análise se relacionam à prática docente dos iniciantes no AEE, à formação docente, às ações alternativas empreendidas pelos iniciantes e às relações profissionais no contexto escolar.

\section{Prática Docente dos Iniciantes no AEE}

O início do exercício profissional na SRM mostrou-se para os iniciantes um período de intensos desafios. Desafios são, neste estudo, considerados como situações a serem superadas pelos professores e que colocam em xeque suas possibilidades profissionais no momento da carreira em que se encontram. Os cinco participantes relataram o período como marcado por dúvidas, medo de errar e desespero, ressaltando percepções como “[...] eu tive medo de não dar conta” (I2), “[...] os primeiros dias, aqui, foi bem desesperador, [...], fiquei bem perdida" (I4), ou, ainda, “[...] talvez erros que pode ser que eu cometi e não estou sabendo [...]” (I5).

Os relatos indicam que os iniciantes vivenciaram o sentimento de sobrevivência, conforme demonstrado por Huberman (1995). Segundo o autor, isso ocorre pela discrepância entre o que foi idealizado na formação inicial e a situação concreta existente, fazendo com que os professores sobrevivam frente à realidade de diferentes formas.

O sentimento de sobrevivência demonstra relação com a precariedade do apoio da escola e das instâncias de gestão da educação em nível de secretaria estadual, representada pelo NRE, a esses professores. Alguns depoimentos são elucidativos:

Educação \& Realidade, Porto Alegre, v. 43, n. 2, p. 747-770, abr./jun. 2018. 753 
Desenvolvimento Profissional de Docentes Iniciantes na Educação Especial

[...] é como se você cai de paraquedas, tem que correr atrás de tudo [...] (I1).

[...] escolhe a escola e vai com Deus [...] (I3).

[...] jogaram a gente na escola (I4).

[...] o Núcleo desova e o resto é contigo [...], eles não ajudam muito a gente, não são tolerantes (I5).

As percepções dos professores demonstram elementos que vão de encontro ao que demonstram os estudos da área, que indicam que para minimizar ou evitar o sentimento de sobrevivência, favorecendo o desenvolvimento profissional docente, o período de iniciação requer um olhar cauteloso sobre o professor, uma postura de assessoramento pela escola e instâncias superiores, uma vez que a experiência negativa pode favorecer o desejo de abandono da profissão (Nono; Mizukami, 2006) e comprometer a efetividade das ações pedagógicas presentes e futuras.

Conforme verificado nos dados, as situações geradoras de sentimentos adversos estão vinculadas principalmente à prática pedagógica a ser desenvolvida com os alunos da educação especial e às atividades burocráticas que envolvem seu trabalho.

Em relação à primeira, um dos participantes relatou que teve dificuldade para saber o "[...] que é certo e o que é errado [...] em termos de ensinar, em termos de fazer com que ele realmente aprenda [...]” (I3). Isso revela que é preciso cautela quando se considera as possibilidades de professores iniciantes na educação especial, especialmente porque, muitas vezes, a formação em nível de graduação ${ }^{4}$ não é direcionada ao atendimento das necessidades educacionais dos alunos público-alvo da educação especial, gerando limitações ao professor.

No que diz respeito às atividades burocráticas, todos os professores expressaram dúvida e insegurança em relação a elas:

[...] o problema são os papéis, relatórios, que a gente tem que estar sempre preenchendo (I1).

A minha falta de conhecimento. Conhecimento da parte burocrática da coisa [...]. De sala de recursos foi toda essa documentação, que eu não sei como a escola teria que, ou, deveria ter uma forma diferente [...] pra que isso não aconteça [...] (I5).

Essas atividades foram relacionadas pelos professores ao processo de avaliação dos alunos para entrada na SRM e posteriormente para os registros sobre sua aprendizagem. Os cinco participantes indicaram o preenchimento de papéis, documentos, bem como a organização de relatórios, atividades que desconheciam, conforme se pode verificar:

[...] aí eu me desesperei. Pensei: 'Eu vou lá no Núcleo’[...]. Não uma ou duas vezes, aí eu falei assim: '(botei a mão na minha cabeça e disse), pelo amor de Deus, [...]! Se você não me disser o que é que eu tenho que fazer naquela sala [...] eu não vou mais [...]'. Aí a [...] pegou toda aquela documentação e me mostrou: Anexo 1, Anexo 2, Anexo 3, Anexo 4, Anexo 5, Anexo 6. Meu Deus, eu olhei tudo aquilo e pensei: 'Jesus amado!' E aí foi assim, ela me explicou um pouco [...] mas também você chega lá assim, e fica: 'Puxa, e agora?' A realidade é outra (I5). 
Segundo os relatos, os professores desconheciam as demandas existentes quando entraram na SRM e buscaram orientação no NRE. Entretanto, esse contato, na maioria das vezes, se deu por telefone e dependeu da disponibilidade dos responsáveis pelo setor de educação especial, conforme se vê nos excertos:

[...] até hoje eu estou descobrindo. Tem coisas que, eu estou lidando hoje com o relatório, estou preenchendo alguma coisa, e aí surgem dúvidas e eu ligo pro pessoal do Núcleo pra eles me passarem (I1).

[...] tudo o que eu precisei, [...], eu ligo, lá, eles me falam tudo, sabe? [...] Mas a questão de como trabalhar com o aluno, isso eu nunca liguei perguntando, não é? (I4).

Eu fui ao Núcleo, eu tentei lá com a [...], ela me orientou, mas também me orientou pouco, só deu umas pinceladas, e ela ficou de me orientar mais, aí ela disse que era pra eu voltar, eu fui umas duas, três ou quatro vezes lá e não a achei (I5).

Os depoimentos indicam a ausência de um tempo/espaço sistemático de assessoramento aos iniciantes para que, em processo formativo, problematizem e compreendam a totalidade da ação docente na SRM. Pela condição apresentada, vê-se comprometido o processo de aprendizagem da docência pelos professores, pois estão sujeitos a procedimentos intuitivos e a respostas imediatistas, reduzidas quanto à possibilidade de favorecerem a compreensão da prática docente e de seus fundamentos. Além disso, é preciso atenção à submissão do docente iniciante a comentários que também desconsideraram essa condição:

[...] quando eu tenho dificuldade, muita, assim, eu vou ao Núcleo, pergunto na área de especial. Ligo, pergunto... Eu sou chata, como esses dias eu liguei: 'Você de novo, professora? Eu não aguento mais'. Eu disse: 'Não, mas é só uma dúvida, que não tem nada a ver com eles, mas sim com a documentação' [...] (I2).

O que se observa é que a forma como foi conduzida a dúvida da professora colocou em xeque sua capacidade de aprendizagem profissional, justamente porque desconsiderou-se a etapa profissional em que se encontrava e as inseguranças surgidas em decorrência dela.

Os achados da pesquisa mostram outros aspectos que parecem interferir diretamente na aprendizagem dos iniciantes no AEE. Um deles se refere à inadequação do espaço físico, e outro, ao trabalho com conteúdos curriculares na SRM.

A inadequação do espaço físico da sala de recursos foi ressaltada por três dos cinco professores, que indicaram que ela muitas vezes é dividida com outros espaços da escola:

[...] falta de uma sala, de um prédio, a sala exclusiva pra sala de recursos [...] (I1).

Nós não temos uma sala nossa [...] é dividida entre sala dos professores, biblioteca, sala de informática, [...], estantes de livros que não são mais 
utilizados ou ainda são utilizados pelos outros professores, e nós, estamos lá. [...] nem espaço físico nós temos [...] (I3).

Minha sala tem isso aqui, é da parede aqui [...] e daqui até lá, é esse quadradinho. Deu duas mesas, [...] e eu pensei: "E agora? [...]” (I5).

Motivado pela falta de espaço adequado, um dos professores relatou que trabalha também com os alunos na biblioteca e ao ar livre (I1). Embora essa iniciativa seja relevante em momentos pontuais, do ponto de vista de atender a certos objetivos em relação à aprendizagem discente, quando utilizada pela necessidade de improvisação, parece perder o sentido.

Quanto às solicitações feitas pelos professores das disciplinas para que sejam trabalhados diferentes conteúdos na sala de recursos, os professores indicaram que tentam atender às diferentes solicitações:

É como essa aí, que me pegou de supetão, regra de três, eu aprendi faz muito tempo. Aí eu tive que dar uma olhada antes, uma noite antes, ver como eu poderia resolver pra explicar pra ele [...] (I2).

Então, a gente acaba sentando e explicando a matéria, e ajudando, você vai fazer o que? (I4).

O que se verifica é a inviabilidade de que os professores da SRM trabalhem com os conteúdos correspondentes à segunda etapa do ensino fundamental, seja pela incompatibilidade de sua formação, que lhes gera insegurança, seja pela inadequação quanto aos objetivos dessa sala. Um dos professores se manifestou a esse respeito, afirmando: “[...] eu não tenho a formação pra trabalhar conteúdo de $6^{\circ}$ ano até o $9^{\circ}$ ano, eu não tenho a formação pra isso" (I1). Observa-se, então, que os professores acabam sendo passivos em relação à situação enfrentada.

Essas constatações indicam que a escola tem um conhecimento limitado da proposta da SRM e de sua relevância para colaborar com a inclusão escolar, pois atribuir-lhe um espaço pequeno ou improvisado ou solicitar que faça reforço escolar podem ser indícios de menosprezo à sua importância em face de outras atividades da escola.

Diante do exposto, parece urgente a iniciativa de um trabalho que privilegie reflexões sobre a SRM no contexto do ensino regular, ainda que se possa acreditar, em nível de sistema de ensino, que ele já exista. Maior atenção e acompanhamento precisam ser dados especialmente quando nessas salas se encontrarem professores iniciantes, pois, conforme se vê, muitas vezes, eles não têm subsídios teórico-práticos para o enfrentamento de situações inusitadas. A desconsideração dessas demandas influencia negativamente a aprendizagem da docência pelos iniciantes na educação especial e, consequentemente, seu desenvolvimento profissional.

\section{Formação Docente}

A formação docente é fundamental para o processo ensino-aprendizagem, e especialmente, quando se discute sobre o desenvolvimento 
profissional docente. Neste estudo, ela é considerada em relação ao ensino-aprendizagem dos alunos público-alvo da educação especial.

Vaillant e Marcelo (2012) entendem que na formação docente a pessoa é quem ativa e, ao fim, quem efetiva sua formação, mas destacam que os contextos de colaboração e de troca favorecem a aprendizagem que leva à melhoria pessoal e profissional.

Em relação aos professores investigados, em que pese sua responsabilidade no contexto escolar inclusivo (Brasil, 2008) e sua condição de iniciantes, dificuldades importantes estão relacionadas à sua formação, especialmente quando se vê que as atribuições dos professores da modalidade envolvem questões como a identificação e o encaminhamento de ações para sanar ou minimizar dificuldades específicas dos alunos, a organização dos atendimentos, o acompanhamento acerca da funcionalidade do que é proposto para a escolarização dos alunos, a orientação a professores do ensino regular e à família, o domínio da tecnologia assistiva (TA), entre outras atribuições (Brasil, 2009) relevantes e que exigem sólido conhecimento profissional.

No caso dos participantes deste estudo, todos têm pós-graduação lato sensu na área da educação especial, uma das condições ${ }^{5}$ que tem sido solicitada para o ingresso nas SRM da rede estadual de ensino pesquisada. Entretanto, não há como desconsiderar que os cinco professores apontaram a fragilidade de sua formação por sua característica essencialmente teórica e que compromete um ensino coerente com as necessidades dos alunos. Alguns excertos exemplificam:

Eu acharia melhor se fosse com estágios, que na pós que eu fiz não tinha estágio. Então, assim, talvez dificulta mais, vendo só na teoria [...] (I1).

Eu acho que deveria ter pelo menos a prática um pouco, sabe? [...] (I2).

Ainda relacionado a esse aspecto foi apontada por três, dos cinco professores, a brevidade ou superficialidade do curso de especialização, aspecto que também comprometeu sua formação, pois os professores se referem ao curso como "fraquinho" (I2), "superficial" (I3) e "rápido" (I4).

Para os professores pesquisados o curso de especialização é central para a atuação na SRM na medida em que nenhum deles tem formação em nível de graduação específica em educação especial, como ocorre em alguns $\operatorname{casos}^{6}$ no país, ficando para a formação continuada tal especificidade. Nesse sentido, ao não vivenciarem nessa formação a perspectiva teórico-prática, os professores sentem-se prejudicados na atuação profissional. Vale ressaltar que a Resolução CNE/CES no 01/2007, que estabelece normas para o funcionamento de cursos de especialização lato sensu no país, não faz referência à relação teórico-prática nesses cursos, limitando-se a definir, no capítulo quinto, que eles “[...] têm duração mínima de 360 horas [...]”(Brasil, 2007, p.1).

Os participantes deste estudo são licenciados em Educação Física (I1, I5), Letras Português/Espanhol (I4, I3) e Pedagogia (I2). A diversidade de formação encontrada indica a imprecisão sobre o que se en- 
tende como necessário para um professor de educação especial. Essa indefinição é também observada na Política Nacional para a área (Brasil, 2008, p. 11) que indica de maneira genérica que, para “[...] atuar na educação especial, o professor deve ter como base da sua formação, inicial e continuada, conhecimentos gerais para o exercício da docência e conhecimentos específicos da área”. Sem definir claramente o que é necessário para essa formação, cabe aos sistemas de ensino a decisão sobre os requisitos para a atuação docente na modalidade, abrindo múltiplas e fragilizadas possibilidades.

Garcia (2010) alertou sobre a indefinição do locus de formação para a área, indicando que aproximadamente nos últimos vinte anos os professores de educação especial foram formados nos cursos de Pedagogia, com habilitação específica na modalidade ou nas áreas das deficiências. Extintas as habilitações em 2006, segundo a autora, tal formação está focada em cursos de pós-graduação. Pelo que se verificou neste estudo, entretanto, a contribuição dessa formação é limitada, comprometendo o desenvolvimento profissional dos iniciantes.

No âmbito da formação docente, é interessante ressaltar como os dois professores formados em Educação Física estabeleceram relação entre sua formação e a prática na SRM. Um deles indicou realizar adaptações (I1) e o outro justificou maior abertura para atuar na área tendo esse curso (I5).

Uma das professoras formadas em Letras Português/Espanhol ressaltou a fragilidade da formação inicial afirmando que saiu "[...] com muitas deficiências na prática” (I3). Outra, formada em Pedagogia, demonstrou a necessidade de estar mais bem preparada para atuar no AEE, tendo em vista obter melhores respostas na aprendizagem dos alunos (I2). Ainda ressaltou que gostaria de “[...] estar pronta, assim, mais do que agora" (I2).

Não se pode deixar de notar nos dados coletados que, ainda que a SRM em que os professores atuam (Tipo I) ${ }^{7}$ receba alunos da segunda etapa do ensino fundamental e que sua formação inicial tenha sido voltada para a atuação nesse nível de ensino em áreas específicas, tanto a formação inicial quanto a continuada em nível de especialização foram insuficientes para a prática pedagógica no AEE. Isso é preocupante na medida em que, embora a legislação defina para esse professor o domínio de conhecimentos gerais para o ensino e específicos para a educação especial (Brasil, 2009), tais níveis de formação não supriram essas necessidades.

A dissociação entre teoria e prática limita a ação pedagógica dos iniciantes, pois foi o aspecto mais ressaltado em relação à especialização. Sendo essa sua formação mais específica para atuar na modalidade, restringiu-se, então, seu desenvolvimento didático-pedagógico (Bolívar, 2002) no âmbito da educação especial, comprometendo o desenvolvimento profissional.

Quanto à formação continuada em serviço, os professores sinalizaram sua inconsistência. Em relação à propiciada pela escola, embora 
tenham indicado tempo semanal destinado à hora-atividade, contraditoriamente não a consideraram como atividade formativa que possibilita revisão, reflexão e redimensionamento da prática pedagógica, o que indica um baixo nível de sistematização desse tempo que deveria contar, inclusive, com a participação da equipe de gestão da escola.

Quanto às iniciativas do NRE e seu papel formativo, os dados indicam afastamento das questões pedagógicas. Os iniciantes afirmaram:

[...] Não, da prática pedagógica não tem, da prática em sala de aula, não. A gente tem o apoio deles no que precisar, mas de apoio pedagógico, por enquanto eu não vi [...] (I1)

A parte pedagógica não. Eu sinto muita dificuldade. Lógico, é meu primeiro ano [...]. Esse ano eu senti muita dificuldade [...] às vezes se você ligar, 'Ah, não teria essa informação?' 'Ah, eu vou ver [...], te ligo depois'! E esse depois nunca aconteceu [...] (I3).

O impacto negativo da fragilidade da formação continuada dos iniciantes é constatado também pelo estranhamento demonstrado em relação ao trabalho a ser realizado na SRM e ao afastamento da reflexão sobre as atribuições do professor dessa sala. Eles afirmaram:

A sala de recurso, eles pedem, é mais material concreto, mas tem coisas que não tem como trabalhar material concreto. Então, infelizmente, você vai ter que fazê-los escrever! (I2).

E, segundo a fala da S. [professora experiente], 'Eles querem que trabalhem jogo' (I4).

Porque aí, aqui não é pra virar repeteco da sala de aula, é o que eles falam (I4).

Os professores não demonstram constituírem-se como protagonistas da prática pedagógica (ainda iniciantes), mas como receptores de propostas externas com restrita compreensão das razões que as fundamentam.

Vale destacar também que eles aproximaram-se da proposta de trabalho da SRM intuitivamente. Isso se deu a partir da observação do que havia nela em termos de materiais pedagógicos, bem como da verificação de atividades desenvolvidas por professores anteriores a eles. Um dos iniciantes afirmou:

Então, quando eu entrei na sala de recursos, a primeira coisa que eu olhei foi jogos. Então, falei: 'Então eu tenho que partir daqui' (I1).

E aí fui pegando os trabalhos dos professores do ano passado, de outros anos e fui vendo o que eles trabalhavam também (I1).

A aproximação da proposta se deu também após indicações de um professor experiente sobre o que correspondia ao trabalho na SRM. Um dos professores salientou que procurou uma amiga, a qual explicou: "Olhe, tem os joguinhos, assim, a gente trabalha isso, aquilo". Ainda assim, declarou que pensou: "Ah, meu Deus, mas com joguinho? Será que o aluno vai aprender com joguinho? [...] Eu não acredito nisso, já viu, joguinho? É má fé!” (I4).

Educação \& Realidade, Porto Alegre, v. 43, n. 2, p. 747-770, abr./jun. 2018. 
Dentre os cinco participantes apenas um solicitou por contato telefônico ao NRE a disponibilização das normas de funcionamento da SRM, pela necessidade de conhecer sua proposta. Destacou: "Quando eu entrei na sala de recursos eu já, logo em seguida, liguei no Núcleo, [...] e falei: 'Eu quero todos os informativos, leis, atributos, tudo', liguei e pedi" (I3).

Verificou-se, assim, que a maioria dos professores não procurou as normativas estaduais da SRM, o que indica pouca preocupação com a existência da documentação. Uma iniciante confirmou esse entendimento: "Então esse lance de legislação eu nem pensei, você é que está me falando agora, [...]" (I5).

Outras atividades formativas, vinculadas ao NRE, foram elencadas pelos professores. Dois deles afirmaram ter participado de uma reunião e não exatamente de uma formação com os demais professores da modalidade quando assumiram a SRM. A reunião não foi exclusiva para os iniciantes. O excerto a seguir ilustra essa constatação:

Quando eu entrei teve aquela reunião [...], pra gente se apresentar. Foi um mês depois. Foi bem rápida, [...], e eles falaram um pouquinho, ah, eu nem vou lembrar direito, [...] sobre essa questão do laudo, [...], que às vezes o laudo é médico, às vezes tem que levar o do psicólogo, mas foi bem rápido, foi uma reunião com todos os professores, [...]. Então, não foi uma coisa específica, [...] (I4).

A reunião foi qualificada pelos iniciantes como breve, tendo ocorrido para tratar de questões gerais sobre a sala de recursos, que pareceram pouco ter contribuído com o exercício e a aprendizagem profissional. Vale destacar, entretanto, que não necessariamente os professores entraram em uma mesma data nas SRM, o que dependeu de quando foram convocados para assumir a função, aspecto que pode ser um complicador para a efetivação de ações formativas com os iniciantes, especialmente por não se configurarem como política específica de formação.

A constatação da contribuição restrita dessa ação se baseia no seguinte depoimento:

Eu vim. Não tive orientação nenhuma, até assumir. Aí quando a gente começou as aulas teve uma pequena formação, que eles só passaram algumas informações, não uma formação (I1).

Duas outras iniciativas relacionadas à SRM foram indicadas pelos participantes. Uma foi um curso específico realizado na modalidade à distância, apontada por dois professores:

Teve, [...] acho que há um mês atrás, [...] uma formação à distância, [...], mas foi bem, só teoria, [...]. Sobre sala de recursos. Era conhecer [...] todas as áreas das deficiências. [...], todas as abrangentes pra salas de recursos. [...]. [...], às vezes eles queriam que no diário a gente colocasse [...], alguma coisa que você trabalhou em sala de aula que você viu que surtiu muito resultado, [...]. Aí a gente fazia o diário, descrevendo atividades, também (I1). 
E depois este curso que teve agora, acho que foi uns dois meses de curso on-line. Esse foi bom. [...]. É aquele que tem fórum, sabe? Troca de ideia com os colegas... Tratou [...] uma questão de você entender o que era, [...], a dislexia, o que era o aluno com problema motor, aí tinha sempre uma atividade envolvendo a escola [...] (I4).

Pela especificidade da atividade formativa, os dois professores demonstraram que em alguma medida o curso trouxe contribuições e, embora um deles tenha afirmado que a formação foi teórica, verifica-se uma aproximação de situações práticas já realizadas por eles, bem como a intenção de socialização dessas práticas, embora não seja possível compreender como se deu a fundamentação desse processo para favorecer o desenvolvimento profissional.

A segunda iniciativa elencada foi presencial e tratou, segundo a depoente, sobre o uso de tecnologias:

Formação em ação:

Cursos de formação, específicos na área de especial. Tanto que a gente teve, agora, de tecnologia, que é uma das áreas que eu tive dificuldade (I2).

A Formação em Ação está relacionada a uma proposta de formação continuada da Secretaria de Estado da Educação em que algumas vezes se determinam temas de estudo e em outras são pré-definidos temas para serem escolhidos pelas escolas. Ela acontece nos dois semestres letivos e cada temática tem materiais específicos ${ }^{8}$. É interessante observar que apenas uma professora a referenciou, o que suscita questionamentos acerca de sua efetividade para contribuir com os iniciantes.

De acordo com este estudo, há importantes dificuldades na formação inicial e continuada dos professores iniciantes nas SRM. Isso contribui para uma limitada expectativa de desenvolvimento profissional desses professores, pois também não há indícios de processos sistematizados de aprendizagem da docência que o favoreçam, o que pode restringir, ainda, a contribuição dos iniciantes com a inclusão escolar.

\section{Ações Alternativas Empreendidas pelos Iniciantes}

Para enfrentar as demandas da prática profissional no AEE os professores iniciantes realizaram diferentes ações, evidenciando suas necessidades. Todos buscaram discutir assuntos pertinentes com outros professores de SRM ou da área de educação especial mais experientes para apoiar suas decisões. Um deles afirmou: "[...] sempre vou, sempre vou observar, procurar conversar com os professores, pra ver como eles trabalham, pra ver se o que eu estou trabalhando está [...]" (I1).

A importância do professor experiente para os iniciantes tem sido relatada por autores que analisam essa etapa profissional (Marcelo, 1999; André, 2012). Por isso tem sido destacado o papel da tutoria para esses professores, pois com ela podem ocorrer interlocuções mais bem estruturadas tendo em vista o avanço da aprendizagem dos iniciantes.

Educação \& Realidade, Porto Alegre, v. 43, n. 2, p. 747-770, abr./jun. 2018. 
Essa é, portanto, uma possibilidade a ser considerada no âmbito da educação especial em escolas inclusivas, ainda que isso demande uma estrutura que a viabilize.

Outra ação empreendida por todos os professores foi o uso da internet para buscar soluções para as diferentes situações. Eles afirmaram, por exemplo:

Eu coloco ‘educação especial' e aí coloco entre parênteses - no Google - o probleminha que ele tem [...], o que for bom pra você, vai pegando e o que não for você vai descartando (I2).

Eu [...] busco na internet, eu vejo uma atividade, 'Ah, porque tem a troca'. Como esse meu aluninho que troca b pelo d. Às vezes é atividade bem tradicional, [...], de complete, [...]. É bem interessante, tem blog... (I4).

$\mathrm{O}$ uso da internet pelos iniciantes se deu de diferentes formas, desde a busca de blogs ${ }^{9}$ e sites com banco de atividades até a procura de vídeos e jogos para os alunos. A internet é um recurso interessante na atualidade e seu uso foi entendido como viável pelos professores. Entretanto, é preciso cautela em relação a como é utilizada, pois com as dúvidas indicadas e a forma como foram solucionadas com esse recurso, corre-se o risco de seu uso pragmático. Isso ocorrerá caso deixem de compreender a prática pedagógica à luz da teoria, da problematização e da troca fundamentada com outros professores da modalidade, deixando de percebê-la como uma prática social em que professor, aluno e conhecimento envolvem-se em um processo complexo.

A necessidade desse cuidado vem também da constatação de que apenas dois dos cinco professores fizeram referência ao uso de bibliografias acadêmicas, como resultados de pesquisa, por exemplo, demonstrando preocupação com a origem e o conteúdo dos materiais. Um deles afirmou: "Busco no Google, trabalhos feitos, ou artigo também. [...]. Porque tem algumas coisas que [...] são simplesmente jogadas na internet e não têm base em nada. [...]" (I1).

Assim como em relação à internet, a procura por livros foi assinalada pelos professores. Mas essa procura também inspira cautela quando considerado o desenvolvimento profissional docente, pois quatro participantes reduzem-na a materiais didático-pedagógicos com modelos de atividades. Dois exemplos são ilustrativos:

Consulto também livros, [...] de primeiro ao quinto ano, [...], que eu busco propostas de produção de texto, da matemática, de situações problemas (I1)

É uma [...] coleçãozinha, dessa professora, até, por sinal. Aí, quando eu fui pra lá, eu olhei todo aquele material, [...], aí tirei um monte de Xerox, quase para o ano todo, [...] (I5).

As alterativas utilizadas pelos iniciantes evidenciam suas necessidades em relação à ação pedagógica no AEE e a fragilidade do seu acompanhamento pela equipe de gestão da escola e pelo NRE ao qual estão vinculados. Os professores demonstraram suprir as demandas da prática profissional, embora nem sempre a forma encontrada possa ter sido a mais adequada para o desenvolvimento profissional docente, uma vez 
que, no caso deste estudo, improviso e ações pouco fundamentadas demonstraram conduzir a prática pedagógica da maioria dos iniciantes.

\section{Relações Profissionais no Contexto Escolar}

Conforme já destacado, para Jordell (1987), as relações pessoais que se dão no contexto da escola são mais importantes para o desenvolvimento profissional dos professores iniciantes do que as que se dão externamente a ele.

Os resultados indicam que os professores estabeleceram trocas com os colegas de trabalho e com os alunos e suas famílias, sendo as trocas com os colegas e com os alunos as que interferiram mais em sua aprendizagem profissional. É necessário notar, entretanto, que a relação com os alunos no caso dos cinco participantes está sustentada em uma ideia de ajuda e proteção, ainda que demonstrem preocupação com sua aprendizagem, conforme se vê nos depoimentos a seguir:

Então eu acho que um pouco o estado de querer ser mãe, e ali, o carinho é demais, [...] eles têm tanto amor pra dar, que parece que eu os conheço há anos, [...] (I2).

Desde sempre, já por esse motivo, acho que de ter essa aptidão, [...], pra ajudar os outros [...] (I3).

A partir dessa constatação vê-se que ainda há necessidade de superação de modelos pedagógicos pautados na "ótica assistencial e caritativa” (Ferreira; Guimarães, 2003, p. 93) presentes por longo tempo na educação especial e que, neste caso, limitam o desenvolvimento profissional dos iniciantes porque inibem a construção de ações profissionais pautadas em conhecimentos pedagógicos.

Outro resultado deste estudo indica uma boa recepção inicial dos cinco professores pela equipe gestora das escolas quando chegaram para assumir a SRM. Entretanto, observou-se que, para quatro desses professores, a experiência de boa receptividade foi relacionada à sua presença anterior nas escolas como professores de outras áreas (educação física, educação de jovens e adultos e espanhol), portanto, sem vínculo exclusivo com sua chegada como professores da educação especial.

Também vale destacar que, apesar de ter sido apontada como positiva tal aproximação inicial, na sequência do trabalho na SRM, a relação com a equipe de gestão e com os professores da escola não foi sempre favorável, pois comportamentos pouco amenos de outros docentes foram sentidos pelos cinco iniciantes. Um dos participantes percebeu olhares curiosos dos professores e seu receio por considerarem que na SRM há poucos alunos (I4). Outro apontou que eles fazem brincadeiras como fazem com professores de educação física, afirmando: "Deixam ficar brincando" (I1). Possivelmente por isso uma das participantes sente-se isolada e afirma: "[...] parece que eu não estou sintonizada com a escola" (I5).

Educação \& Realidade, Porto Alegre, v. 43, n. 2, p. 747-770, abr./jun. 2018. 
Os dados indicam o ressentimento dos professores, possivelmente motivado pela percepção de isolamento (I5) e de desconfiança em relação ao seu trabalho (I1, I4) por serem professores da SRM. Isso compromete seu desenvolvimento profissional na medida em que interfere na formação da identidade docente, o que ocorre pela percepção negativa de como são vistos pelos colegas (Moita, 1995).

Um dos professores ainda declarou:

É diferente, porque você chega lá, já está a equipe montada, tem professor que ela [a pedagoga] já conhece e aí, eu não sou muito de estar conversando, eu converso, [...], mas eu fico na minha (I2).

Tal preocupação confirma a conclusão de Basurto López (2012) de que a chegada do iniciante da educação especial na escola regular caracteriza-se pela busca de espaço nesse contexto. Assim, há dificuldade pelo fato de não se sentir membro da escola, possivelmente pelo vínculo com a modalidade de educação especial, que historicamente foi paralela ao contexto da escola regular (Ferreira; Guimarães, 2003).

Outro resultado que chama a atenção em relação à curiosidade dos professores da escola em relação ao AEE é também a conclusão de quatro participantes de que a escola conhece pouco sobre o trabalho da SRM, especialmente os docentes e a equipe de gestão. Isso impacta na percepção que os iniciantes têm da inviabilidade de ações de colaboração ou de assessoria pela escola, conforme se pode verificar nos seguintes exemplos:

Porque a escola não me deu estrutura, eles não sabem. Pra eles é novo (I2).

O que eles sempre falam, 'Ah, é uma coisa nova, eu estou me inteirando, também, tentando me inteirar' (I4).

A percepção do pouco conhecimento da escola em relação ao AEE é confirmada também pela constatação de que os iniciantes procuraram os pedagogos e diretores das escolas centralmente para a resolução de questões burocráticas ou incidentes envolvendo alunos e pais. Todos indicaram essa postura, exemplificada no depoimento a seguir:

Ela me ajudou bastante, no início, [...], mais pra orientar onde está isso, onde está aquilo [...]. Se por acaso eles estão faltando, ela ajuda [...], já vai fazer bilhete, vai chamar pai, vai conversar com o pai pra vir até o colégio [...] (I1).

A atividade das pedagogas e diretoras em relação a esses professores demonstra restringir-se ao atendimento de intercorrências. Não há referência à sua participação na formação docente em serviço ou no desenvolvimento de um trabalho conjunto que tenha em vista a reflexão sobre as questões de ensino e aprendizagem, que, sabe-se, apesar das dificuldades existentes, é atribuição da equipe de gestão (Franco, 2008).

Diante da referência ao limitado conhecimento da escola sobre o AEE mostra-se necessária a atenção das instâncias superiores de gestão educacional a esse aspecto, uma vez que, conforme já referido, os 
iniciantes necessitam de apoio para avançar em sua prática pedagógica, e a escola necessita estabelecer maior interlocução com a educação especial.

Destaca-se, assim, a importância do NRE no contexto da formação continuada, seja aquela a ser proporcionada à escola como um todo, seja, especialmente, a voltada aos professores iniciantes na educação especial, através da proposição de espaços de reflexão e estudo específicos. Tal situação demonstra a urgência de políticas públicas para professores em período de iniciação profissional, conforme já indicado por André (2012). Nesse caso, atendendo às especificidades dos iniciantes no AEE.

Outro aspecto interferente no desenvolvimento profissional dos iniciantes foi apontado por quatro participantes e diz respeito à construção das primeiras iniciativas de trabalho conjunto com os demais professores da escola. Eles indicaram incompatibilidade de horário para encontrarem com a maioria dos docentes das disciplinas cursadas pelos alunos do AEE e, em alguns casos, com a pedagoga do turno em que esses alunos frequentam o ensino regular, pois o AEE realiza-se em contraturno.

Em um dos depoimentos relatou-se:

[...] professor de sala de recursos deveria trabalhar as 40 horas, [...], porque aí, [...] eu mesma faço a ponte, eu mesma consigo conversar com os professores da manhã, porque se você só fica à tarde, você atende no contraturno, você não tem o contato com o professor da manhã... (I5)

Ainda em relação a esse aspecto, dois professores apontaram que, para contatar com os professores do ensino regular, aproveitam o tempo de trabalho na escola como professores de outras áreas (I1, I4), o que confere a essa ação um caráter de improviso. Ainda, duas professoras afirmaram ir à escola em outro horário, por sua iniciativa, mesmo não estando lá para desempenhar outra atividade (I2, I3), conforme exemplifica o depoimento a seguir:

Sim, mas algumas vezes eu vou lá, de manhã. [...]. Eu procuro ir lá pela manhã pelo menos a cada 20 dias pra saber como está o desenvolvimento deles (I3).

Observou-se assim, que há preocupação dos iniciantes com o desenvolvimento do trabalho na SRM em face da dificuldade do contato com os professores do ensino regular, pois essa é uma necessidade inerente a esse trabalho. Tal dificuldade gera o improviso e limita processos melhor estruturados de trocas e estudos entre os professores, impactando ainda no planejamento conjunto em vista do desenvolvimento profissional docente e do objetivo de formação integral dos alunos da educação especial. 


\section{Considerações Finais}

Este estudo propôs-se a explicitar os desafios vivenciados por professores iniciantes na profissão e no atendimento educacional especializado, tendo em vista seu desenvolvimento profissional.

Os dados demonstraram que os iniciantes têm dificuldades importantes relacionadas à sua prática pedagógica. Essas dificuldades dizem respeito ao limitado conhecimento do trabalho a ser desenvolvido na SRM, bem como à forma de realizá-lo. Elas se relacionam também aos aspectos burocráticos envolvidos no seu funcionamento.

Esses elementos desencadearam dúvidas e medo de errar nos professores iniciantes, além do sentimento de desespero. Isso demonstra relação com a falta de acompanhamento dos professores tanto pela escola quanto pelo NRE e, ainda, com a fragilidade da formação específica em nível de especialização que cursaram. As iniciativas do NRE e da escola são lacunares e não favoreceram o desenvolvimento profissional dos iniciantes, pois pouca atividade formativa e de assessoramento foi realizada, o que os conduziu a aprendizagens profissionais limitadas, vinculadas a buscas pragmáticas para a superação dos desafios.

Entraves importantes foram indicados pelos iniciantes, como a incompatibilidade de horários com os professores do ensino regular com os quais devem interagir, o pouco envolvimento da equipe de gestão com o seu trabalho, a ausência de assessoramento, o desconhecimento da escola sobre a SRM, a pouca compreensão que têm sobre a burocracia existente.

Diante dos resultados obtidos, conclui-se que os múltiplos desafios vivenciados pelos iniciantes os conduziram a processos imediatistas e improvisados de solução das demandas existentes. Estratégias de sobrevivência e de cópia foram as que mais se manifestaram para a resolução de situações da prática profissional. Os resultados indicaram que ainda que possuam formação específica em nível de pós-graduação lato sensu, o assessoramento pelas escolas e instâncias superiores se faz necessário.

Além disso, não exclusivamente, vê-se a possibilidade de que esse assessoramento possa lançar mão da modalidade à distância, de maneira estruturada, fundamentada, interativa, como rede de colaboração (Vaillant; Marcelo, 2012). Essa pode ser uma das alternativas viáveis em nível de sistema de ensino, uma vez que os iniciantes minimizam dúvidas buscando quaisquer recursos da internet.

Sendo a expressão da prática, entende-se que o desenvolvimento profissional dos professores iniciantes pesquisados parece limitado, requerendo a revisão das demandas existentes na SRM, pois, tal como se apresentam, os colocam diante de um paradoxo que em última instância não favorece também a inclusão escolar.

Recebido em 23 de outubro de 2016 Aprovado em 23 de abril de 2017 


\section{Notas}

1 Educandos com deficiência, transtornos globais do desenvolvimento e altas habilidades/superdotação (Brasil, 2008). De acordo com Araújo e Neto (2014, p. 14) no DSM-5 os transtornos globais do desenvolvimento "[...] foram absorvidos por um único diagnóstico, Transtornos do Espectro Autista." Juntamente com a deficiência intelectual, eles fazem parte dos Transtornos do Neurodesenvolvimento (Araújo; Neto, 2014). No Paraná, de acordo com a Deliberação CEE/CP no 02/2016, é assegurado atendimento educacional especializado também aos alunos com transtornos funcionais específicos, considerados no documento como "[...] aqueles que apresentam transtorno de aprendizagem, como disgrafia, disortografia, dislexia, discalculia ou transtorno de deficit de atenção/hiperatividade, entre outros" (Paraná, 2016, p. 8).

2 As SRM ofertam o AEE e têm equipamentos, materiais didáticos e mobiliários específicos para o atendimento às necessidades especiais dos alunos (Brasil, 2011).

3 CAAE: 01693612.6.0000.0105.

4 A Res. no 1/CNE/2002 previa genericamente que a formação docente para a educação básica propiciasse "[...] conhecimentos sobre as especificidades dos alunos com necessidades educacionais especiais [...]” (Brasil, 2002, p. 3). Atualmente a Res. no 2/CNE/2015 indica brevemente para a formação inicial de professores em nível superior a garantia de conteúdos relacionados à "[...] educação especial [...]" (Brasil, 2015, p.12) que favoreçam a consciência da diversidade e o respeito às diferenças relacionadas a "[...] necessidades especiais [...]" (Brasil, 2015, p. 8).

5 Para o ingresso na rede estadual tem sido solicitada formação específica por meio de diferentes possibilidades: formação em Estudos Adicionais, especialização em nível médio, habilitação em educação especial, pós-graduação em educação especial, educação física adaptada.

6 Garcia (2010) indicou o registro de dois cursos de graduação em educação especial no país, sendo um considerado mais antigo, da Universidade Federal de Santa Maria e outro, mais recente, da Universidade Federal de São Carlos (UFSCar). Atualmente esses cursos são ofertados também em outras instituições de ensino superior.

7 Salas de recursos de Tipo II são destinadas a alunos com deficiência visual e de Tipo I, a alunos com as demais deficiências. Com a Deliberação CEE/CP no 02/2016 (Paraná, 2016) há previsão de salas de recursos multifuncionais em deficiência intelectual, transtornos globais de desenvolvimento, transtornos funcionais específicos; em surdez; em deficiência visual; e em altas habilidades ou superdotação.

8 Mais detalhes em: http://www.educadores.diaadia.pr.gov.br/modules/conteudo/conteudo.php?conteudo=1341. Acesso em: 16 out. 2015.

9 Sobre o uso de blogs por professores de educação especial consultar o trabalho de Rios (2014) disponibilizado on-line pelo Observatório Nacional de Educação Especial (ONEESP). 
Desenvolvimento Profissional de Docentes Iniciantes na Educação Especial

\section{Referências}

ANDRÉ, Marli. Políticas e Programas de Apoio aos Professores Iniciantes no Brasil. Cadernos de Pesquisa, São Paulo, v. 42, n. 145, p. 112-129, 2012.

ANDRÉ, Marli et al. Desafios no Processo de Constituição da Profissionalidade de Professores Iniciantes. In: CONGRESSO INTERNACIONAL SOBRE PROFESSORADO PRINCIPIANTE E INSERÇÃO PROFISSIONAL À DOCÊNCIA, 4., 2014, Curitiba. Anais... Curitiba: UTFPR, 2014. 1 CD-ROM.

ARAÚJO, Álvaro Cabral; NETO, Francisco Lotufo. A Nova Classificação Americana para os Transtornos Mentais. Revista Brasileira de Terapias Comportamentais e Cognitivas, São Paulo, p. 67-82, v. 16, n. 1, abr. 2014. Disponível em: <http://pepsic.bvsalud.org/scielo.php?script=sci_arttext\&pid=S1517-55452014000100007>. Acesso em: 09 abr. 2017.

BARDIN, Laurence. Análise de Conteúdo. Lisboa: Edições 70, 2004.

BASURTO LÓPEZ, Maria Esther. La Docencia Novel en Educación Especial. In: CONGRESO INTERNACIONAL SOBRE PROFESORADO PRINCIPIANTE E INSERCIÓN PROFESIONAL A LA DOCENCIA, 3., 2012, Santiago do Chile. Anais.. Santiago do Chile: UA, 2012. 1 CD-ROM.

BOLÍVAR, Antonio. Profissão Professor: o itinerário profissional e a construção da escola. Bauru: EDUSC, 2002.

BRASIL. Resolução CNE/CP no 1, de 18 de fevereiro de 2002. Institui Diretrizes Curriculares Nacionais para a Formação de Professores da Educação Básica, em nível superior, curso de licenciatura, de graduação plena. Brasília, 2002. Disponível em: <http://portal.mec.gov.br/seesp/arquivos/pdf/res1_2.pdf>. Acesso em: 22 abr. 2014.

BRASIL. Resolução CNE/CES nº 1, de 08 de junho de 2007. Estabelece normas para o funcionamento de cursos de pós-graduação lato sensu, em nível de especialização. Brasília, 2007. Disponível em: <http://portal.mec.gov.br/ index.php?option=com_docman\&view=download\&alias=8825-rces001-07pdf\&category_slug=setembro-2011-pdf\&Itemid=30192>. Acesso em: 04 jul. 2017. BRASIL. Política Nacional da Educação Especial na Perspectiva da Educação Inclusiva. Brasília: MEC/SEESP, 2008. Disponível em: <http://peei.mec.gov.br/ arquivos/politica_nacional_educacao_especial.pdf $>$. Acesso em: 08 ago. 2015.

BRASIL. Resolução CNE/CEB no 4, de 2 de outubro de 2009. Institui Diretrizes Operacionais para o Atendimento Especializado na Educação Básica, modalidade Educação Especial. Brasília, 2009. Disponível em: <http://portal.mec.gov. br/dmdocuments/rceb004_09.pdf >. Acesso em: 22 abr. 2014.

BRASIL. Resolução CNE/CP no 2, de $1^{\circ}$ de julho de 2015. Define as Diretrizes Curriculares Nacionais para a formação inicial em nível superior (cursos de licenciatura, de formação pedagógica para graduados e de segunda licenciatura) e para a formação continuada. Brasília, 2015. Disponível em: <http://portal. mec.gov.br/index.php?option=com_docman\&view=download\&alias $=17719$ res-cne-cp-002-03072015\&category_slug=julho-2015-pdf\&Itemid=30192>. Acesso em: 11 ago. 2015.

BRASIL. Decreto no 7.611, de 17 de novembro de 2011. Dispõe sobre a educação especial, o atendimento educacional especializado e dá outras providências. Diário Oficial [da República Federativa do Brasil], Brasília, 2011. Disponível em: <http://www.planalto.gov.br/ccivil_03/_Ato2011-2014/2011/Decreto/ D7611.htm\#art11>. Acesso em: 15 jan. 2012.

768 Educação \& Realidade, Porto Alegre, v. 43, n. 2, p. 747-770, abr./jun. 2018. 
CASTORIADIS, Cornelius. A Experiência do Movimento Operário. São Paulo: Brasiliense, 1985.

CASTRO, Juliana; VAZ, Alexandre. Professores no Atendimento Educacional Especializado: responsabilidades e impossibilidades. Arquivos Analíticos de Políticas Educativas, Tempe, v. 23, n. 33, mar. 2015. Disponível em: <http://epaa. asu.edu/ojs/article/view/1667/1576>. Acesso em: 09 set.2015.

CLARK, Christopher M.; PETERSON, Penelope L. Teachers' Thought Processes. In: WITTROCK, Merlin (Org.). Handbook of Research on Teaching. 3.ed. Nova York: Macmillan, 1986.

FERREIRA, Maria Elisa; GUIMARÃES, Marly. Educação Inclusiva. Rio de Janeiro: DP\&A, 2003.

FRANCO, Maria Amélia. Coordenação Pedagógica: uma práxis em busca de sua identidade. Múltiplas Leituras, v. 1, n. 1, p. 117-131, jan./jun. 2008. Disponível em: <https://www.metodista.br/revistas/revistas-ims/index.php/ML/article/ view/1176/1187>. Acesso em: 04 set. 2015.

GARCIA, Rosalba Maria. Educação Especial. In: OLIVEIRA, Dalila Andrade; DUARTE, Adriana; VIEIRA, Lívia Fraga. (Org.). Dicionário de Trabalho, Profissão e Condição Docente. Belo Horizonte: UFMG, 2010. 1 CD-ROM.

GARCIA. Política de Educação Especial na Perspectiva Inclusiva e a Formação Docente No Brasil. Revista Brasileira de Educação, Rio de Janeiro, v. 18, n. 52, jan./mar. 2013. Disponível em: <http://www.scielo.br/pdf/rbedu/v18n52/07. pdf>. Acesso em: 01 fev. 2015.

HUBERMAN, Michaël. O Ciclo de Vida Profissional dos Professores: diários biográficos. In: NÓVOA, António (Org.). Vidas de Professores. Porto: Porto, 1995.

IMBERNÓN, Francisco. La Formación y el Desarrollo Profesional del Profesorado: hacia uma nueva cultura profesional. Barcelona: Graó, 1998.

INSTITUTO NACIONAL DE ESTUDOS E PESQUISAS EDUCACIONAIS ANÍSIO TEIXEIRA. Censo Escolar da Educação Básica 2013: resumo técnico. Brasília, 2014. Disponível em: <http://portal.inep.gov.br/resumos-tecnicos>. Acesso em: 6 out. 2015.

JORDELL, Karl Oynvind. Structural and Personal Influences in the Socialization of Beginning Teachers. Teaching e Teacher Education, Grã-Bretanha, v. 3, n. 3, p. 165-177. 1987.

LUNDGREN, Ulf P. Model Analyses of Pedagogical Processes. Studies in Education and Psychology, Stockholm, Stockholm Institute of Education, Department of Educational Research, n. 2, 1977.

MARCELO, Carlos. Formação de Professores: para uma mudança educativa. Porto: Porto, 1999.

MARQUEZINE, Maria Cristina; LEONESSA, Viviane; BUSTO, Rosângela. Professor de Educação Especial e as Dificuldades do Início da Prática Profissional. Educação Especial, Santa Maria, v. 26, n. 47, p. 699-712, set./dez. 2013. Disponível em: $<$ http://www.ufsm.br/revistaeducacaoespecial>. Acesso em: 15 jul. 2015.

MARTINS, Pura Lucia Oliver. Os Princípios Didáticos na Ação Docente: conhecimento como expressão da ação docente. In: ROMANOWSKI, Joana Paulin; MARTINS, Pura Lucia Oliver; JUNQUEIRA, Sérgio Rogério (Org.). Conhecimento Local e Conhecimento Universal: pesquisa, didática e ação docente. Curitiba: Champagnat, 2004.

MICHELS, Maria Helena. O que Há de Novo na Formação de Professores para a Educação Especial? Educação Especial, Santa Maria, v. 24, n. 40, p. 219-232, 
Desenvolvimento Profissional de Docentes Iniciantes na Educação Especial

maio/ago. 2011. Disponível em: <http://cascavel.ufsm.br/revistas/ojs-2.2.2/index.php/educacaoespecial/article/view/2668/2440 >. Acesso em: 10 fev. 2013.

MOITA, Maria Conceição. Percursos de Formação e Transformação. In: NÓVOA, Antonio. (Org.). Vidas de Professores. Porto: Porto, 1995.

NONO, Maévi Anabel; MIZUKAMI, Maria da Graça Nicoletti. Processos de Formac,ão de Professoras Iniciantes. REUNIÃO ANUAL DA ANPED, 29., 2006,

Caxambu. Anais... Caxambu: 2006. Disponível em: <http://www.anped.org. br>. Acesso em: 13 set. 2013.

PARANÁ. Deliberação CEE/CP no 02, de 15 de setembro de 2016. Dispõe sobre as Normas para a Modalidade Educação Especial no Sistema Estadual de Ensino do Paraná. Curitiba, 2015. Disponível em: <http://www.cee.pr.gov.br/arquivos/File/pdf/Deliberacoes/2016/Del_02_16.pdf>. Acesso em: 04 jul. 2017.

ROVEDA, Patrícia Oliveira et al. Professores Principiantes: dificuldades da docência superior. In: CONGRESSO INTERNACIONAL SOBRE PROFESSORADO PRINCIPIANTE E INSERÇÃO PROFISSIONAL À DOCÊNCIA, 4., 2014, Curitiba. Anais... Curitiba: UTFPR, 2014. 1 CD-ROM.

THOMPSON, Edward Palmer. A Miséria da Teoria ou um Planetário de Erros. Rio de Janeiro: Zahar, 1981.

TRIVIÑOS, Augusto Nibaldo Silva. Introdução à Pesquisa em Ciências Sociais: a pesquisa qualitativa em educação. São Paulo: Atlas, 1987.

VAILLANT, Denise; MARCELO, Carlos. Ensinando a Ensinar: as quatro etapas de uma aprendizagem. Curitiba: UFPR, 2012.

Silmara de Oliveira Gomes Papi é professora do Departamento de Educação da Universidade Estadual de Ponta Grossa.

E-mail: silmarapapi@gmail.com 